\title{
Process optimization for the removal of environmental contaminants from fish oils
}

\author{
Jeroen MAES ${ }^{1}$ \\ José VILA AYALA ${ }^{1}$ \\ Bruno DE MEULENAER ${ }^{2}$ \\ Roland VERHÉ ${ }^{3}$ \\ Véronique $\mathrm{GIBON}^{1}$ \\ Wim DE GREYT ${ }^{1}$ \\ ${ }^{1}$ Desmet-Ballestra Group, Minervastraat 1,
B-1930 Zaventem, Belgium
<MA/@desmetballestra.com>
${ }^{2}$ Department of Food Safety and Food Quality,
Faculty of Bioscience Engineering,
Chent University, Coupure Links 653,
B-9000 Gent, Belgium
${ }^{3}$ Department of Organic Chemistry,
Faculty of Bioscience Engineering,
Chent University, Coupure Links 653,
B-9000 Gent, Belgium
}

Omega-3 fatty acids, such as eicosapentaenoic acid (EPA) and docosahexaenoic acid (DHA) are abundantly present in fatty fish and fish oils. During the seventies, the beneficial health effects of consumption of these fatty acids were already being linked to the low incidence of cardiovascular diseases (Bang Ho et al., 1971, 1976). Later epidemiological studies illustrated a correlation between the intake of these compounds and a reduced risk for arterial thrombosis, cardiovascular diseases, multiple sclerosis, and autoimmune and inflammatory disorders (Dyerberg et al., 1978; Kromann et Green, 1980; Dewailly et al., 2001a, b). Moreover, omega-3 fatty acids are claimed to be essential for normal growth and development, and they play an important role in the prevention and treatment of hypertension, cancer, and several inflammatory or autoimmune disorders (Simopoulos, 1991).

These beneficial effects are in great contrast with the presence of persistent organic pollutants (POPs) such as pesticides, polychlorobifenyls (PCBs), hexachlorobenzene, and polychlorinated dibenzo- $p$-dioxins and

\begin{abstract}
Fish oils are rich in nutritionally valuable omega-3 components, mainly eicosapentaenoic (EPA) and docosahexaenoic (DHA) fatty acids. Unfortunately, they could also be contaminated with a series of toxic pollutants like PCDD/Fs and PCBs. This article focuses on the methods for removal of these unwanted compounds and at the same time preserving the nutritional quality of fish oil. Adsorption, deodorization, packed column stripping, and a combination of processes are reviewed here. Activated carbon at $0.5 \%$ dosage was efficient in adsorbing PCDD/Fs and no- PCBs, but only $58 \%$ of the mo- PCBs could be removed. Adsorption treatment did not significantly alter the quality of the oil. Simple packed column stripping and/or deodorization removed no-PCBs, and especially mo-PCBs in a better manner, its efficiency increasing with temperature. Nutritional properties were preserved until $210^{\circ} \mathrm{C}$, beyond which significant EPA and DHA degradation was observed. Combination of activated carbon treatment and deodorization was a good method to remove contaminants, yet preserving the nutritional quality of fish oil. At deodorization temperature of $190^{\circ} \mathrm{C}$ and $0.1 \% A C$ dosage, the total contamination level of PCDD/Fs and dioxin-like PCBs could be reduced, independent of the process sequence, from 35 to below $10 \mathrm{pg} T E Q / g$, in accordance with the European Union (EU) regulation.
\end{abstract}

Key words: omega-3 fatty acids, dioxins, PCBs, decontamination, refining, fish oil -furans (PCDD/Fs), mainly originating from the environment.

Intake of dioxins can cause a broad range of toxic effects in the human body, including teratogenecity and carcinogenicity (Safe, 1990). In the PCB fraction, the non-ortho or coplanar (no-PCBs) and mono-ortho chlorinesubstituted congeners (mo-PCBs) are considered as being the most important compounds from a toxicological point of view. They can cause the same adverse effects as dioxins, and therefore are generally referred to as 'dioxinlike' PCBs (dl-PCBs). Levels of dioxins and dlPCBs are expressed as "toxic equivalents" (TEQ), a value which represents the total "2,3,7,8-TCDD equivalent toxic potency" of a mixture of dioxin-like compounds.

In 2002, a maximum PCDD/F-level for food and feed purposes of, respectively, 2 and $6 \mathrm{pg}$ TEQ/g in fish oils was established by the European Commission (Unanimous, 2001). A legislation regarding maximally accepted dl-PCB levels in fish oils was accepted in 2006 (Unanimous, $2006 a, b)$. The total sum of dioxins and dl-PCBs should not exceed $10 \mathrm{pg} T E Q / g$ dl$P C B s$ in fish oil intended for human consump- tion, and $24 \mathrm{pg}$ TEQ/g dl-PCBs in fish oil for animal feed. These regulations have important consequences for the fish processing industry. Today, about $2 \%$ of the total fats and oils produced in the world are fish oils, used in omega3-enriched margarines, nutraceuticals (e.g. omega-3-enriched products), and animal feeds (Barlow, 1992).

Removal of contaminants is an important issue for the fish oil processors. At the same time, this process must also preserve the nutritional quality of the oil. The goal of this article is to compare the different processes and to describe optimal process conditions to make a compromise between detoxification and preservation of the nutritional quality. The first objective was to investigate the efficiency of different adsorbents for the removal of contaminants and more specifically dl-PCBs. In parallel, the possibilities of stripping techniques and combined processes (adsorption followed by deodorization and vice versa) were investigated. Nutritional and oxidative qualities were investigated before and after the decontamination treatment. 


\section{Experimental procedures}

\section{Raw material}

Neutralized and winterized cod-liver oil from Icelandic origin was used as a feedstock for all the trials.

\section{Adsorbents}

A series of commercially available adsorbents were used in this study: filter aid, silica powder, bleaching earth. and activated carbon.

\section{Adsorption test procedure}

Neutralized and winterized cod-liver oil (400 g) was preheated in a rotary evaporator to $70^{\circ} \mathrm{C}$ under reduced pressure (20 mbar). A set amount $(0.1$ or $0.5 \% \mathrm{w}: \mathrm{w})$ of a selected adsorbent was added to the pre-heated oil. Oil and adsorbent were mechanically mixed in the same rotary evaporator for $30 \mathrm{~min}$ at $70^{\circ} \mathrm{C}$ under reduced pressure (20 mbar). The mixture of oil and adsorbent was then filtered over a Buchner filter covered with Whatman $\mathrm{N}^{\circ} 1$ filter paper. A second safety filtration over another Buchner filter covered with Whatman $N^{\circ} 1$ filter paper was applied in order to ensure complete removal of the adsorbent. The treated samples were stored in the dark under nitrogen atmosphere and at refrigeration temperature $\left(4^{\circ} \mathrm{C}\right)$ to minimize quality deterioration.

\section{Packed column stripping}

The tests were carried out in a continuous pilot installation according to the procedure described by Ayala et al. (2007). The reaction conditions were as follows: flow rate, $13.5 \mathrm{~kg} / \mathrm{h}$; estimated processing time, approx. $7 \mathrm{~min}$; column diameter, $7.62 \mathrm{~cm}$; column packing, $2 \mathrm{~m}$ length with $250 \mathrm{~m}^{2} / \mathrm{m}^{3}$ specific surface area; top pressure, $4 \mathrm{mbar}$; pressure drop, $2 \mathrm{mbar}$; top temperature, $180-220^{\circ} \mathrm{C}$ with $10^{\circ} \mathrm{C}$ interval.

\section{Laboratory-scale batch deodorization}

Lab-scale deodorization was performed in a house-made glass batch lab-deodorizer, with maximum load capacity of $400 \mathrm{~g}$. Vacuum was pulled from the top with a vacuum pump, and the pressure was regulated to 1.2 mbar with a needle valve. Water vapor (1.1\%) was injected at the bottom of the flask. The deodorization was stopped after $60 \mathrm{~min}$. Condensed material was collected in a double-jacketed water cooler.

\section{Analytical methods}

Nutritional and oxidative quality. The feedstock and treated cod-liver oil samples were characterized using the official methods and recom- mended practices by the American Oil Chemists' Society (AOCS) (Anonymous, 1990): peroxide value (Cd 8-53), paraanisidine value ( $\mathrm{Cd} 18-90)$, vitamin $\mathrm{E}$ content (Ce 8-89), and fatty acid composition (Ce 1b89 combined with Ce 1e-91). For the vitamin A content, saponification and extraction were carried out according to International Union of Pure and Applied Chemistry (IUPAC) Method 2.411 (Anonymous, 1987), and injected on a Varian LiChosorb 10 RP 18 HPLC column.

Contaminant analysis. Gas chromatography in combination with high-resolution mass spectrometry (GC-HRMS) was used for the detection of PCDD/Fs and dl-PCBs in the oil samples. The analyses were carried out at the University of Liège. A detailed description of the GCHRMS analysis is given by Focant et al. (2003). Calculations were carried out using the most recent World Health Organization (WHO) toxic equivalent factors (TEFs), established by Van Den Berg et al. (2006).

\section{Results and discussion}

\section{Adsorption tests with different types of adsorbent}

The feedstock contained $6.3 \mathrm{pg}$ TEQ/g dioxins, $29.0 \mathrm{pg}$ TEQ/g no-PCBs, and $1.9 \mathrm{pg}$ TEQ/g moPCBs to yield a total contamination of $37.2 \mathrm{pg}$ $T E Q / g$. In figure 1, the purification efficiency of the different adsorbents at two concentrations is shown. The treatments with filter aid, silica powder and bleaching earth at concentrations of 0.1 and $0.5 \%$ did not significantly reduce the levels of dioxins and dl-PCBs. Only the activated carbon proved to efficiently reduce the contaminant levels in fish oil. High dosage $(0.5 \%)$ reduced the level of PCDD/Fs with $99.9 \%$, and with $98.8 \%$ at low dosage (0.1\%). Full removal of no-PCBs was observed with $0.5 \%$ AC, where only $58 \%$ of the mo-PCBs could be adsorbed. Earlier tests had shown a removal of $40 \%$ mo-PBCs from contaminated cod-liver oil with this adsorbent under similar conditions (Maes, 2003). Under the applied conditions, activated carbon treatment could reduce the level of contaminants below the limit of $10 \mathrm{pg}$ TEQ/g PCDD/Fs + dl-PCBs set by European Legislation (Unanimous, 2006).

The peroxide value (PV) increased slightly in all the samples after the adsorbent treatment, but remained acceptably low. None of the treatments significantly modified the anisidine value (AnV) and altered the vitamin E content. On the contrary, the concentration of vitamin A decreased, proportionally to the amount of adsorbent added. The fatty-acid composition and more specifically the levels of EPA and DHA, was not altered by the adsorption processes (data not shown). Any of the adsorption processes did not negatively affect the oxidative and nutritional quality of the fish oil, in accordance with earlier results published by Maes et al. (2003).

\section{Packed column stripping trials}

The PCDD/F and dl-PCB levels in cod-liver oil after packed column stripping at different temperatures $\left(180-220^{\circ} \mathrm{C}\right)$ are shown in figure 2 . It was observed that the temperature had a very

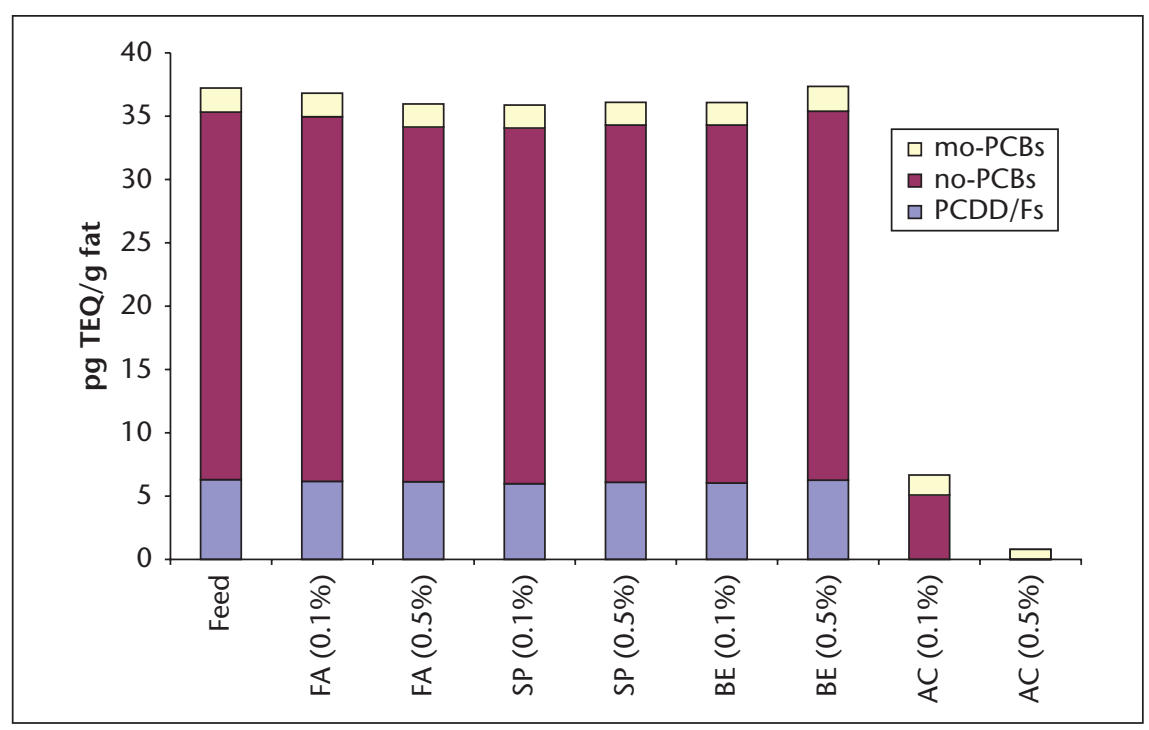

Figure 1. Levels of $P C D D / F s$ and $d l-P C B s$ in cod-liver oil before and after adsorption treatment $\left(70{ }^{\circ} \mathrm{C}, 0.1\right.$ or $0.5 \%$ adsorbent, $30 \mathrm{~min}$ reaction time) with different types of adsorbents ( $F A=$ filter aid, $S P=$ silica powder, $B E=$ bleaching earth, $A C=$ activated carbon). 


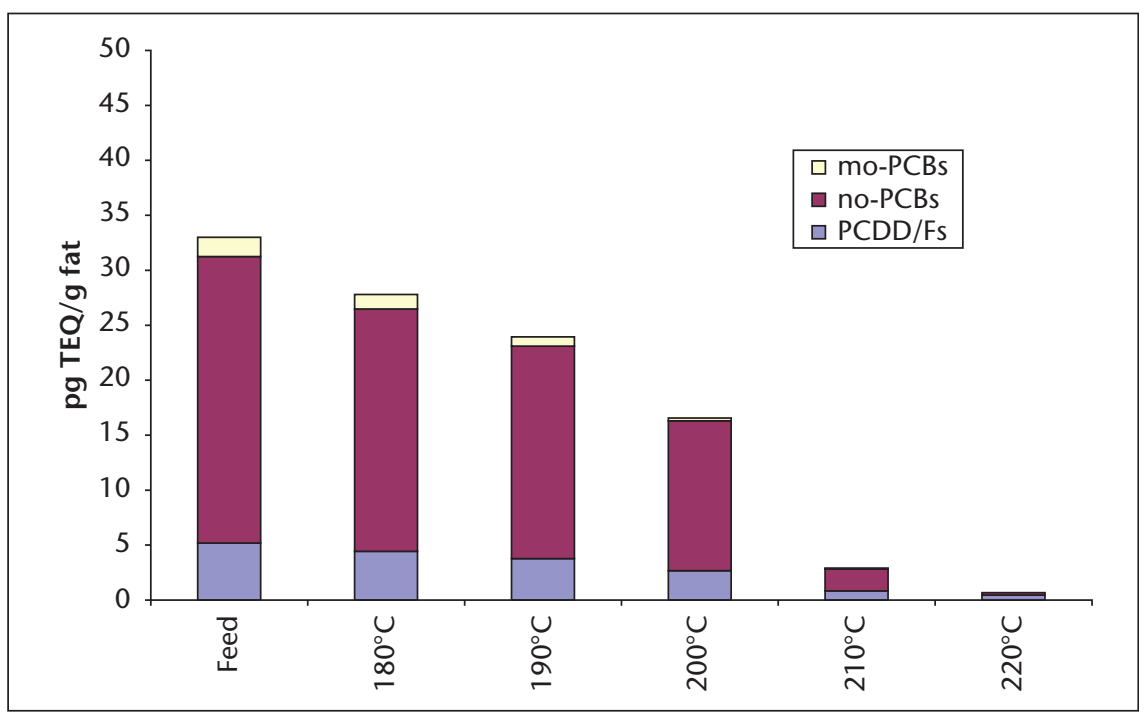

Figure 2. Levels of $P C D D / F s$ and dl-PCBs in cod-liver oil before and after packed column stripping (4\% steam injection, top pressure $=4$ mbar, $\Delta p=2$ mbar.

pronounced effect on the reduction of PCDD/ Fs and dl-PCBs. The best reduction was obtained in the level of mo-PCBs. At $200{ }^{\circ} \mathrm{C}$, $86 \%$ of the mo-PCBs were removed, while over $50 \%$ of the PDCC/Fs and no-PCBs remained in the oil. Already at $210^{\circ} \mathrm{C}$, all contaminants were efficiently removed to wellbelow the limit of $10 \mathrm{pg}$ TEQ $/ \mathrm{g}$ PCDD/Fs + dlPCBs set by European Legislation (Unanimous, 2006).

All stripped oil samples were characterized by a decrease in PV; during stripping, peroxides present in the oil were broken down, with no significant differences between the different trials. Unfortunately, the break-down of perox- ides gave rise to an increase in AnV. There was no significant difference in AnV between oil stripped at 180 and $220^{\circ} \mathrm{C}$. Within the applied temperature conditions, omega- 3 fatty acids content was not affected (data not shown). The healthy components of the oil were not significantly modified during the stripping experiments.

\section{Lab-scale deodorization trials}

The PCDD/F and dl-PCB levels in cod-liver oil after lab-scale deodorization at different temperatures $\left(180-220^{\circ} \mathrm{C}\right)$ are shown in figure 3 . Similar to the packed column stripping trials,

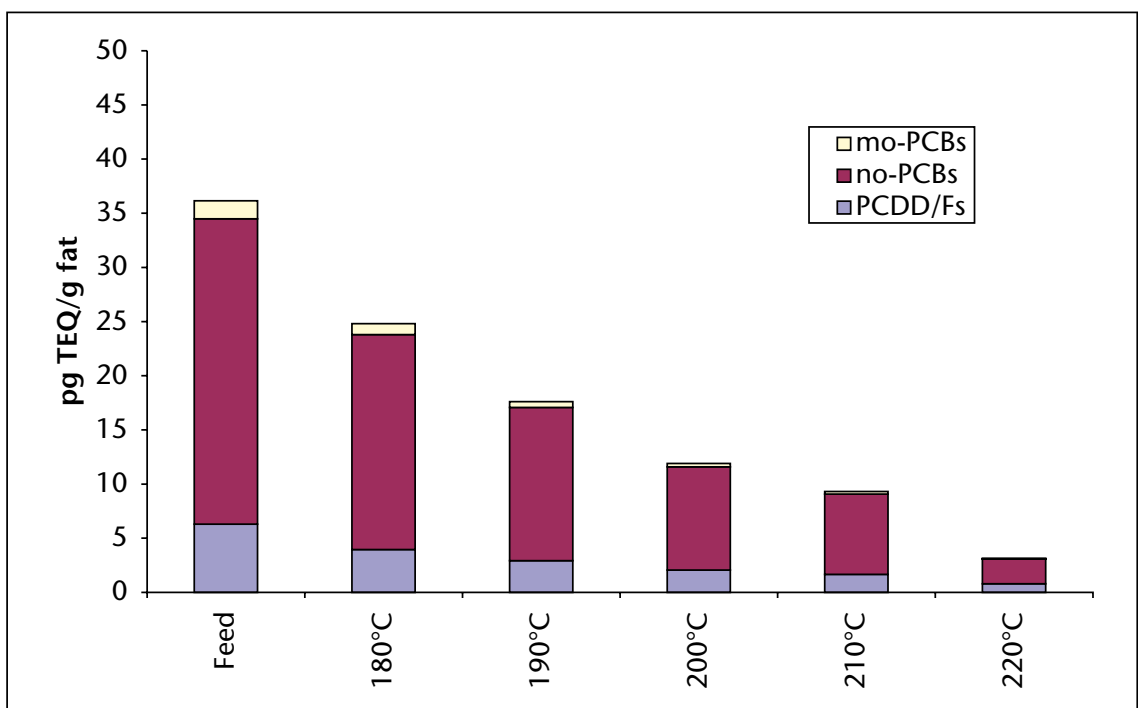

Figure 3. Levels of $P C D D / F s$ and dl-PCBs in cod-liver oil before and after lab-scale batch deodorization ( $1.1 \%$ steam injection, pressure $=1.2 \mathrm{mbar}, 60$ min residence time $)$ increase of temperature had a pronounced effect on the decontamination efficiency. This effect was faster below $200^{\circ} \mathrm{C}$ than during stripping, resulting in good removal (both $67 \%$ ) of PCDD/Fs and dl-PCBs at this temperature. However, the specification of $10 \mathrm{pg}$ TEQ/ $g$ PCDD/Fs + dl-PCBs set by European Legislation (Unanimous, 2006) was only achieved at $210^{\circ} \mathrm{C}$.

The deodorization treatment had a similar effect on the PV as packed column stripping. Between 180 and $200{ }^{\circ} \mathrm{C}$, the breakdown of peroxides gave rise to an increase in AnV. However, when deodorization temperature reached $210{ }^{\circ} \mathrm{C}$, the $A n V$ dropped significantly by vacuum removal of volatile secondary oxidation products (data not shown). Figure 4 shows the effect of increased deodorization temperatures on the levels of omega- 3 fatty acids EPA and DHA. Until $210^{\circ} \mathrm{C}$, no or little effect on the omega-3 content could be observed, while from $220^{\circ} \mathrm{C}$, the content of EPA and DHA started to decrease. At $260^{\circ} \mathrm{C}$, the levels of EPA and DHA dropped below $50 \%$ of the initial concentration.

\section{Combined adsorbent treatment and deodorization}

The following step was to investigate the combined effects of activated carbon treatment and mild deodorizing conditions (at relatively low temperature). The deodorization trials were performed at $190^{\circ} \mathrm{C}$ in order to preserve the nutritional quality and oxidative properties of the oil. Activated carbon was used as an adsorbent in concentrations of 0.1 and $0.5 \%$. The level of contaminants before and after combined treatment is shown in figure 5. The tests indicate that the sequence in which ACtreatment and deodorization are done has no influence on the decontamination efficiency. After deodorization combined with adsorption on $0.5 \% \mathrm{AC}$, almost a total removal of $\mathrm{PCDD} / \mathrm{Fs}$ and no-PCBs, and over $75 \%$ removal of moPCBs could be obtained. Whereas AC has proven to be very efficient for adsorbing PCDD/Fs and no-PCBs (figure 1), most of the remaining mo-PCBs were removed during deodorization. With lower AC dosage (0.1\%), around $65 \%$ of mo-PCBs were removed with the combined treatment.

All treated samples were characterized by low PV. Secondary oxidation products (AnV) slightly increased. Vitamin A content, and EPA and DHA levels were not significantly affected (results not shown). Activated carbon treatment combined with 'mild' stripping (below $200{ }^{\circ} \mathrm{C}$ ) did not significantly affect the nutritional quality and oxidative properties of the oil. 


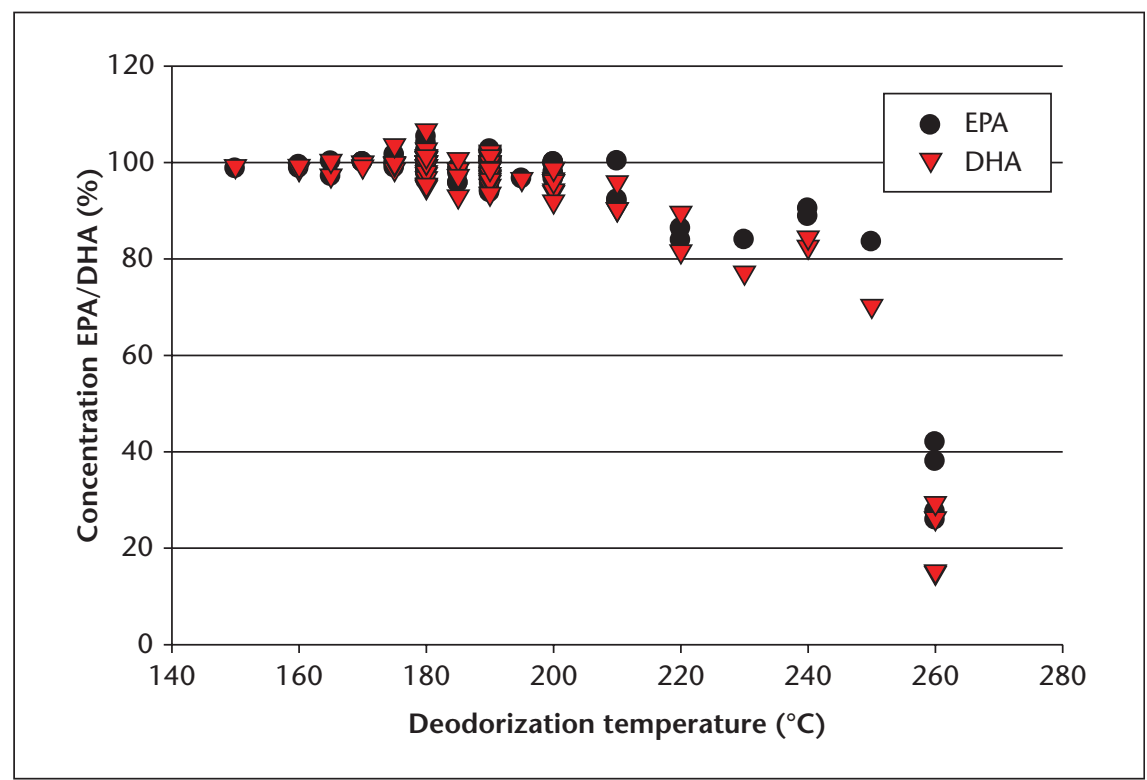

Figure 4. Levels of EPA and DHA, relative to the initial concentration, after lab-scale batch deodorization at different temperatures.

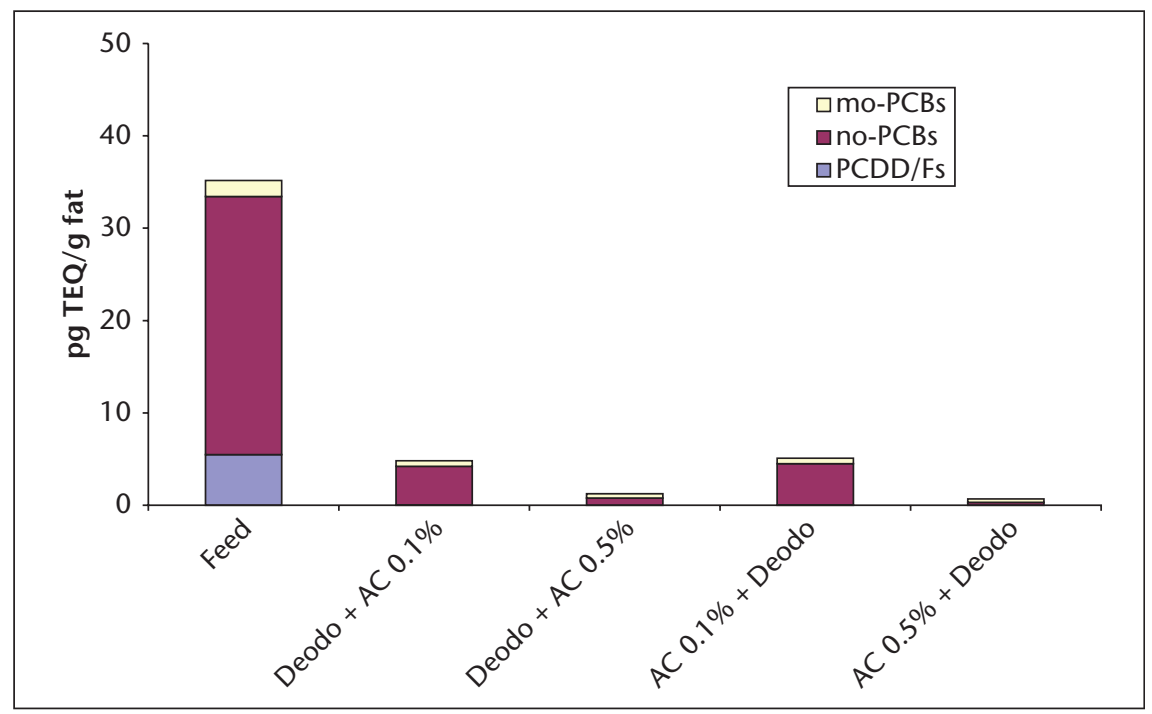

Figure 5. Levels of $P C D D / F s$ and dl-PCBs in cod-liver oil before and after lab-scale batch deodorization $\left(190^{\circ} \mathrm{C}\right.$, pressure $=1.2 \mathrm{mbar}, 1.1 \%$ steam injection, 60 min residence time $)$ in combination with activated carbon treatment $\left(70{ }^{\circ} \mathrm{C}, 0.1\right.$ or $0.5 \%$ adsorbent, 30 min reaction time).

\section{General conclusions}

Activated carbon was found to be the best adsorbent for the removal of PCDD/Fs and dl-PCBs from fish oil. With $0.5 \% \mathrm{AC}$, total removal of $\mathrm{PCDD} / \mathrm{Fs}$ and no-PCBs was obtained, though more than $40 \%$ of the moPCBs remained in the oil. Apart from some vitamin A adsorption, the treatment did not significantly alter the quality of the oil.

During stripping and deodorization, PCDD/Fs, no-PCBs, and mo-PCBs were better removed with increasing temperature. The best reduc- pendent of the process sequence. According to De Kock et al. (2006), the sequence of AC treatment, followed by mild stripping at lower temperatures should be considered as the next generation process in fish oil refining.

Acknowledgments. The authors kindly acknowledge Prof. Leo Goeyens and Dr. Sophie Carbonnelle from the Institute of Public Health (Brussels, Belgium), and Prof. Edwin De Pauw and Dr. Gauthier Eppe from the Université de Liège, Faculty of Sciences (Liège, Belgium) for the contaminant analysis and their involvement throughout the research project. This research was cofinanced by the Belgian Federal Service of Public Health, Safety of the Food Chain and the Environment.

\section{RÉFÉRENCES}

Ayala JV, Caillauw G, Foubert I, et al. Impacts of bleaching and packed column steam refining on cocoa butter properties. JAOCS 2007; 84: 1069-77.

Anonymous. Official methods and recommended practices of the American oil chemists' Society. Champaign, IL: AOCS Press, 1990.

Anonymous. Standard methods for the analysis of oils, fats and derivatives. Oxford, United Kingdom: Blackwell Scientific, 1987.

Bang HO, Dyerberg J, Nielsen A. Plasma lipid and lipoprotein pattern in Greenlandic west coast Eskimos. Lancet 1971; 1: 1143-5.

Bang $\mathrm{HO}$, Dyerberg J, Hjorne N. The composition of food consumed by the Greenland Eskimos. Acta Medica Scandinavia 1976; 200: 69-73.

Barlow SM. New uses and new challenges for fish oil. In: Oils and fats in the nineties, Shukla VKS, Gunstone FD, eds. Denmark : Snoghøj, Fredericia, IFSC, 90-102, 1992.

De Kock J, De Greyt W, Vila J, Kellens M. Technologies for cleaning oils and meals. Paper presented EWOS workshop on cleaning oils and meals, Norway: Byrkjedalstunet, 2006.

Dewailly E, Blanchet C, Gingras S, et al. Relations between n-3 fatty acid status and cardiovascular disease risk factors among Quebecers. Am I Clinical Nutr 2001; 74: 603-11.

Dewailly E, Blanchet C, Lemieux S, et al. n-3 Fatty acids and cardiovascular disease risk factors among the Inuit of Nunavik. Am / Clinical Nutr 2001; 74: 464-73.

Dyerberg J, Bang HO, Stofferson E, Moncada S, Vane JR. Eicosapentanoic acid in prevention of thrombosis and atherosclerosis. Lancet 1978; 2: 117-9.

Focant J. Dioxins and related compounds in biological samples, development and apllication of rapid analytical methods. Doctorate study. Belgium: Université de Liège, Faculty of Sciences, 2003. 
Kromann N, Green A. Epidemiological studies in the Upernavik district, Greenland. Incidence of some chronic diseases 1950-1974. Acta Medica Scandinavia 1980; 208: 401-6.

Maes J. The influence of dioxin removing techniques on the quality of fish oil. Master's dissertation. Ghent University, Faculty of Agricultural and Applied Biological Sciences, Belgium, 2003.

Maes J, De Meulenaer B, Van Heerswynghels $P$, et al. Removal of dioxins and $P C B$ from fish oil by activated carbon and its influence on the nutritional quality of the oil. JAOCS 2003; 82: 593-7.
Safe S. Polychlorinated biphenyls (PCBs), dibenzo-pdioxins (PCDDs), dibenzofurans (PCDFs), and related compounds: Environmental and mechanistic considerations which support the development of toxic equivalent factors (TEFs). Critical Reviews Toxicology 1990; 24: 51-88.

Simopoulos AP. Omega-3 fatty acids in health and disease and in growth and development. Am J Clinical Nutrition 1991; 54: 438-63.

Unanimous. Council Directive 2001/102/EC of 27 November 2001. Official Journal European Communities 2001; 6: 45-9.
Unanimous. Commission Regulation (EC) No 199/2006 of 3 February 2006. Official Journal European Communities 2006; 32: 34-8.

Unanimous. Commission Directive 2006/13/EC of 3 February 2006. Official Journal European Communities 2006; 32: 44-52.

Van Den Berg M, Birnbaum LS, Denison M, et al. The 2005 World Health Organization reevaluation of human and mammalian toxic equivalent factors for dioxins and dioxin-like compounds. Toxicological Sciences 2006; 93: 223-41. 